\title{
Alkaline citrate reduces stone recurrence and regrowth after shockwave lithotripsy and percutaneous nephrolithotomy
}

\author{
Lojanapiwat B, Tanthanuch M, Pripathanont C, Ratchanon S, Srinualnad S, Taweemonkong- \\ sap T, Kanyok S, Lammongkolkul S
}

Division of Urology, Department of surgery (BL), Chiangmai University; Division of Urology, Department of surgery (MT, CP), Prince Songkla University; Division of urology, Department of surgery (RS), Chulalongkorn University; Division of urology, Department of surgery (SS, TT), Siriraj hospital, Mahidol University; Department of biochemistry (SK, SL), Siriraj hospital, Mahidol University, Thailand

\begin{abstract}
Objective: To evaluate the preventive effects of alkaline citrate on stone recurrence as well as stone growth post-ESWL or PCNL in patients with calcium-containing stones.

Materials and Methods: A total of 76 patients with calcium calculi who were stone-free or had residual stones less than 4 $\mathrm{mm}$ following ESWL and PCNL were enrolled. All patients were independently randomized into two groups. The treated group $(\mathrm{N}=39)$ was given $81 \mathrm{mEq}$ per day of oral potassium-sodium citrate $(27 \mathrm{mEq}$ three times a day), and the untreated group $(\mathrm{N}=37)$ serving as controls. Blood, twenty-four hour urine analysis, and plain KUB were measured and compared at the baseline and after 12 months.

Results: At baseline, hypocitraturia was found in 20 of 39 patients (46.05\%) of Group I and 15 of 37 patients (40.5\%) of Group II. At 12 months, hypocitraturia was found in 3 of 39 (7.69\%) and 14 of 37 (37.83\%) of Group I and Group II, respectively $(\mathrm{p}=0.007)$. At the 12 month follow-up, of the stone-free group, $92.3 \%$ of the treated group and $57.7 \%$ of the control group were still stone free. Of the residual stone group, 30.8\% and $9.1 \%$ of treated and control group were stone-free, respectively. The increased stone size found in $7.7 \%$ and $54.5 \%$ of treated and control groups, respectively. Conclusion: Sodium-potassium citrate provides positive effects on stone-forming activities in calcium stone patients suffering from urolithiasis following treatment with ESWL and PCNL procedures at the 12-month follow-up.
\end{abstract}

Key words: kidney; calculi; lithotripsy; citrates; urolithiasis

Int Braz J Urol. 2011; 37: 611-616

\section{INTRODUCTION}

With the advantage of high efficiency and low morbidity rates, extracorporeal shock wave lithotripsy (ESWL) has become the therapy of choice for small renal stones. Percutaneous nephrolithotomy (PCNL) is also becoming the therapy of choice for large renal stones due to the less invasive procedure as compared to open nephrolithotomy. These therapies provide good results, associated with an acceptable rate of complications, but unfortunately they do not change the underlying metabolic abnormality. Stone recurrence is usually found after either treatment, even in those with a stone-free post-therapy status. In addition, retained stone fragments following those therapies may reaggregate or constitute a nucleus for new stone formation, thereby causing a high rate of stone growth (1-4). The patient's chances of first episode recurrent stone formation range between $27 \%$ and $50 \%(5,6)$. Medical treatment should therefore be considered following these interventions, in order to prevent further secondary treatments and hospitalizations. Among the metabolic disorders usually found in recurrent stone forming patients, hypocitraturia 
(low urinary citrate) is an important risk factor for calcium nephrolithiasis (1-4). Several studies demonstrated the effect of alkaline citrate in prevention and/or reduction of the stone recurrence and stone growth (1-4). In the current study, we evaluated the preventive effects of potassium-sodium citrate on stone recurrence as well as stone growth post-ESWL or PCNL, in patients with calcium-containing stones.

\section{MATERIALS AND METHODS}

The study was approved by the ethics committee of the Faculty of Medicine, Chiang Mai University. Patients gave written informed consent before participating in the study.

Eighty patients, who were stone-free or had residual stone fragments with less than $4 \mathrm{~mm}$ diameter at eight weeks after ESWL or PCNL, were enrolled in the present clinical study. In case of ESWL, patients were treated by using Storz ${ }^{\mathrm{TM}}$ Modulith SL-20 equipment; in case of PCNL a standard nephroscopy (26-Fr Storz ${ }^{\mathrm{TM}}$ nephroscope) under fluoroscopic guidance with combined ultrasound and pneumatic lithotripsy was performed. All patients had calcium stones after the analysis by infrared spectrometry method. Four patients were excluded from the study due to loss of follow-up $(\mathrm{N}=3)$ and unsatisfactory compliance with medication $(\mathrm{N}=1)$. In total, 76 patients completed the one-year followup period. Eight weeks after the ESWL/PCNL therapies, plain KUB films were evaluated: 39 patients were stone-free $(E S W L n=24$, PCNL $n=15)$ and 37 had residual stones smaller than $4 \mathrm{~mm}$ in diameter $($ ESWL $n=26$, PCNL $n=11)$.

All patients were independently block randomized into two groups: the treated group and the untreated group. The treated group $(n=39)$ was given 81 $\mathrm{mEq}$ oral potassium-sodium citrate (Uralyt-U®, Rottapharm Madaus) per day ( $27 \mathrm{mEq}$ three time a day), whereas the control group $(n=37)$ received no treatment. All patients had normal renal function and normal renal anatomy, as assessed by preoperative intravenous pyelography study. All patients who had urinary tract infections, anatomic abnormalities and clinical history of urologic stone surgery were excluded.

At baseline, all patients were evaluated for blood urea nitrogen (BUN) creatinine, electrolytes, complete blood count (CBC), calcium, uric acid, urinalysis; in the 24-hour urine study, total urine volume, creatinine, electrolyte, calcium, oxalate, Uric acid?

Uric acid and citrate were also measured. Patients were advised to have sufficiently high fluid intake throughout the study, and the follow-up was scheduled every 3 months.

The patients were reevaluated at six months after the initial treatment for serum chemistry and urinalysis. After 12 months, all patients were evaluated for serum chemistry, urinalysis, 24-hour urine study and plain KUB. The evidence of new stone formation was determined by spontaneous stone passage in absence of preexisting stones and/or appearance of new stones on a plain KUB film. Growth of existing stones was determined by quantification of increased stone size.

The statistical analyses were carried out using SPSS statistics software. Mann-Whitney U tests were used to compare laboratory tests, remission rates, and growth rates between groups. The difference within each group between baseline and 12 months post treatment was assessed by repeated measurement ANOVA and multivariate analysis.

The protocol and documents needed for this study have been reviewed and approved by the Ethics Committees of each participating hospital.

\section{RESULTS}

Of 80 patients recruited, 76 patients completed the 12-month follow-up observation period. The average ages were $51.7 \pm 10.4$ and $48.9 \pm 10.7$ years for the treated and control groups, respectively (Table-1). The average BMI was $23.9 \pm 3.7$ $\left(\mathrm{kg} / \mathrm{m}^{2}\right)$ in treated group and $23.6 \pm 3.2\left(\mathrm{~kg} / \mathrm{m}^{2}\right)$ in control group. The untreated group consisted of 25 patients $(67.6 \%)$ post-ESWL and 12 patients (32.4\%) post- PCNL. The treated group consisted of 25 patients $(64.1 \%)$ post-ESWL and 14 patients (35.9\%) post-PCNL. The average stone size in CIRF patients was $2.54 \mathrm{~mm}$ and $2.65 \mathrm{~mm}$ in treated and untreated patients, respectively. Laboratory tests such as complete blood count (CBC), blood urea nitrogen (BUN), creatinine, calcium, uric acid and sodium, chloride and bicarbonate did not show any significant difference at 6 months and 12 months as 
Table 1 - Profiles of patients at baseline.

\begin{tabular}{|c|c|c|c|c|}
\hline & \multicolumn{2}{|c|}{ Stone free } & \multicolumn{2}{|c|}{ Residual Fragment $<4$ mm } \\
\hline & $\begin{array}{c}\text { Citrate } \\
(N=13)\end{array}$ & $\begin{array}{l}\text { Control } \\
(N=26)\end{array}$ & $\begin{array}{l}\text { Citrate } \\
(N=26)\end{array}$ & $\begin{array}{l}\text { Control } \\
(N=11)\end{array}$ \\
\hline \multicolumn{5}{|l|}{ Sex } \\
\hline Male & $7(53.8 \%)$ & $17(65.4 \%)$ & $19(73.1 \%)$ & $9(81.8 \%)$ \\
\hline Female & $6(46.2 \%)$ & $9(34.6 \%)$ & $7(26.9 \%)$ & $2(18.2 \%)$ \\
\hline Age (year) & $\begin{array}{c}48.8 \pm 8.26 \\
(35-64)\end{array}$ & $\begin{array}{c}54.1 \pm 10.12 \\
(32-73)\end{array}$ & $\begin{array}{c}49.1 \pm 12.04 \\
(28-75)\end{array}$ & $\begin{array}{c}45.9 \pm 8.93 \\
(31-57)\end{array}$ \\
\hline \multicolumn{5}{|l|}{ Post treatment } \\
\hline ESWL & $8(61.5 \%)$ & $16(61.5 \%)$ & $17(65.4 \%)$ & $9(81.8 \%)$ \\
\hline PCNL & $5(38.5 \%)$ & $10(38.5 \%)$ & $9(34.6 \%)$ & $2(18.2 \%)$ \\
\hline
\end{tabular}

compared with the baseline values, in both groups. Only a significant increase of serum potassium, albeit well within the physiological range, was found in the treated group at 12 months (from $4.02 \pm 0.42$ to $4.29 \pm 0.48 \mathrm{mEq} / \mathrm{L}, \mathrm{p}=0.011)$. Urine $\mathrm{pH}$ and urine potassium were significantly increased from baseline at 6 months and 12 months $(p=0.001$ at 6 month, $p=0.09$ at 12 month). The level of urine potassium in treated patient was significant increased from $27.7 \pm 18.3$ to $56.7 \pm 25.4$ at 6 months and to $49.5 \pm 36.4$ at 12 months. At baseline, the result of 24-hour urine measurement for total urine volume, sodium, potassium, chloride, creatinine, calcium, magnesium, oxalate uric acid, and citrate did not show significant difference between both groups (Table-2). The average values of citrate were 304.3 $\pm 233.8 \mathrm{mg} / \mathrm{d}$ and $259.2 \pm 214.7 \mathrm{mg} / \mathrm{d}$ in control and in treated group, respectively. Hypocitraturia, with citrate values lower than $320 \mathrm{mg} /$ day was found in 35 out of the total 76 patients which was $46.05 \%$ of total patients, 15 patients in control group (92.9 $\pm 64.96 \mathrm{mg} /$ day $)$ and 20 in treated group $(169.5 \pm$ $98.4 \mathrm{mg}$ /day). Mean urine citrate level at month 12 was $305.3 \pm 233.08 \mathrm{mg} /$ day in control group and $405.3 \pm 305.44 \mathrm{mg} /$ day in treated group which is statistically significant $(P=0.007)$. Low urine output (urine volume lower than $1,500 \mathrm{ml} / \mathrm{d}$ ) was a common secondary finding observed in $40.8 \%$ of all patients. Number of patients in both groups who have abnormal 24-hour urine measurement was shown in Table-2.
The change of the stone, assessed at 12 months follow up, is shown in Table-3. In the stonefree group at baseline, $92.3 \%$ of treated group and $57.7 \%$ of control group were still stone free at 12 months. An increase in stone size was found in 7.7\% and $42.3 \%$ of treated and control group, respectively, which were statistically different. At the same 12-month follow-up, in the group with residual stone fragments $<4 \mathrm{~mm}$ in diameter, $30.8 \%$ and $9.1 \%$ of patients were found to be stone-free in the treated and control groups, respectively. $50 \%$ of patients in the treated group showed the same stone size, whereas an increase in stone size was found in $7.7 \%$ and $54.5 \%$ of the treated and control groups, respectively.

\section{DISCUSSION}

The most common composition of kidney stones is calcium-based, which is up to $80 \%$ of all types of stones (7). The purposes of stone management are complete stone clearance, prevention of new stone formation and regrowth, preservation of renal function, control of urinary tract infections and, whenever the case, correction of abnormal anatomy and underlying metabolic abnormality. The advancement in minimally invasive surgery, most kidney stones are treated with extracorporeal shock wave lithotripsy (ESWL) and percutaneous nephrolithotomy (PCNL). Following these treatments, the achievement of stone-free condition or of residual fragments with a diameter smaller than $4 \mathrm{~mm}$ is de- 
Table 2 - 24 hours urine metabolic evaluation.

\begin{tabular}{|c|c|c|c|}
\hline Urine 24 hours & $\begin{array}{c}\text { Citrate } \\
(\mathrm{N}=39)\end{array}$ & $\begin{array}{l}\text { Control } \\
(\mathbf{N}=37) \\
\end{array}$ & P-value \\
\hline \multicolumn{4}{|c|}{ Total volume $(<1500 \mathrm{~mL} /$ day $)$} \\
\hline Month 0 & $17(43.6 \%)$ & $14(37.8 \%)$ & \\
\hline Month 12 & $15(38.5 \%)$ & $20(54.1 \%)$ & 0.331 \\
\hline \multicolumn{4}{|c|}{ Hypercalciuria ( $>300 \mathrm{mg} / \mathrm{d}, \supset^{\Uparrow} ;>250 \mathrm{mg} / \mathrm{d}}$, \\
\hline Month 0 & $4(10.3 \%)$ & $7(18.9 \%)$ & \\
\hline Month 12 & $8(20.5 \%)$ & $7(18.9 \%)$ & 0.391 \\
\hline \multicolumn{4}{|c|}{ Hyperoxaluria (> 40 mg/d) } \\
\hline Month 0 & $8(20.5 \%)$ & $6(16.2 \%)$ & \\
\hline Month 12 & $8(20.5 \%)$ & $10(27.0 \%)$ & 0.476 \\
\hline \multicolumn{4}{|c|}{ Hyperuricouria (> $600 \mathrm{mg} / \mathrm{d}$ ) } \\
\hline Month 0 & $1(2.6 \%)$ & 0 & \\
\hline Month 12 & $1(2.6 \%)$ & $3(8.1 \%)$ & 0.171 \\
\hline \multicolumn{4}{|c|}{ Hypocitraturia (<320 mg/d) } \\
\hline Month 0 & $20(51.3 \%)$ & $15(40.5 \%)$ & \\
\hline Month 12 & $3(7.69 \%)$ & $14(37.83 \%)$ & 0.007 \\
\hline \multicolumn{4}{|l|}{ Urine pH } \\
\hline Month 0 & $5.8 \pm 0.77$ & $5.7 \pm 0.66$ & \\
\hline Month 12 & $\begin{array}{c}6.6 \pm 0.97 \\
(\mathrm{P}=0.001)\end{array}$ & $\begin{array}{l}5.9 \pm 0.70 \\
(\mathrm{P}=0.09)\end{array}$ & \\
\hline
\end{tabular}

Table 3 - Stone-forming activity at 12 months (Overall $n=76$ ).

\begin{tabular}{|c|c|c|c|c|c|c|}
\hline & \multicolumn{3}{|c|}{ Stone free $(\%)$} & \multicolumn{3}{|c|}{ Residual Fragment $<4$ mm (\%) } \\
\hline & $\begin{array}{l}\text { Citrate } \\
n=13\end{array}$ & $\begin{array}{l}\text { Control } \\
n=26\end{array}$ & $\begin{array}{c}\text { RR } \\
(95 \% \mathrm{CI})\end{array}$ & $\begin{array}{l}\text { Citrate } \\
n=26\end{array}$ & $\begin{array}{c}\text { Control } \\
n=11\end{array}$ & $\begin{array}{c}\text { RR } \\
(95 \% \mathrm{CI})\end{array}$ \\
\hline Stone free & $12(92.3)$ & $15(57.7)$ & $\begin{array}{c}5.33 \\
(0.77-36.5)\end{array}$ & $8(30.8)$ & $1(9.1)$ & $\begin{array}{c}1.38 \\
(0.96-1.98)\end{array}$ \\
\hline Stone size unchanged & - & - & & $13(50.0)$ & $2(18.2)$ & $\begin{array}{c}1.47 \\
(0.98-2.18)\end{array}$ \\
\hline Stone size decreased & - & - & & $3(11.5)$ & $2(18.2)$ & $\begin{array}{c}0.83 \\
(0.39-1.76)\end{array}$ \\
\hline $\begin{array}{l}\text { Stone recurrence / } \\
\text { Stone size increased }\end{array}$ & $1(7.7)$ & $11(42.3)$ & $\begin{array}{c}0.19 \\
(0.03-1.28)\end{array}$ & $2(7.7)$ & $6(54.5)$ & $\begin{array}{c}0.30 \\
(0.08-1.0)\end{array}$ \\
\hline
\end{tabular}

fined as a therapeutical success $(1,2)$. The presence of residual fragments is commonly found following these modern treatments, particularly after ESWL $(1,2,8)$. It is clinically relevant, as a recognized predisposing factor for new stone formation (1-4), recurrent urinary tract infections, pain and, in general, for need of further additional treatments (1).

By analyzing stone-forming activity at two years following ESWL, it was found that the incidence of recurrent stones ranged from $8 \%$ to $10 \%$ in stone-free patients and from $20 \%$ to $22 \%$ in patients with residual fragments (8). Another study found recurrent calculi, in patients who had stone free status after ESWL, ranging from $7 \%$ to $14 \%$ per year (9). In comparing Soygur's and Fine's studies at 12 months after ESWL, the alkaline citrate-treated patients who were stone-free at baseline and remained stone-free were $100 \%$ and $89.5 \%$, respectively. However, there were found to be only $71.4 \%$ and $50 \%$ in untreated patients of both studies respectively $(2,10)$. Nine per- 
cent of patients following PCNL had recurrent stones following achievement of stone-free condition, and $63 \%$ had either new calculi or continued stone growth after having residual stone fragments (3).

Metabolic abnormalities were also detected in the majority of patients with recurrent nephrolithiasis. The wide range of underlying metabolic abnormalities such as hypercalciuria, hyperoxaluria, hyperuricouria and hypocitraturia can cause the formation of stones in the urinary tract metabolic abnormalities were not affected following ESWL / PCNL therapies. Our common metabolic abnormalities are hypocitraturia followed by hypercalciuria and low urine output, which is the same as the previous study from Thailand (11). Effective medical management should therefore be directed primarily towards correction of the underlying abnormalities. As expected, stone-free status and residual fragments status following ESWL and PCNL still increased the risk for active stone formation $(1,2,10)$. Such medical treatment significantly alleviated stone-forming activity after ESWL and PCNL in patients who resulted stone-free as well as those with residual fragments $(1,2,10)$. The remission rate of patients with residual calculi was significantly lower than the stone-free group (1-4).

Citrate is the most potent stone inhibitor $(12,13)$. The mean normal urinary citrate excretion is $640 \mathrm{mg} / 24$ hours of urine. The accepted limit for diagnosing hypocitraturia is $320 \mathrm{mg} / 24$ hours of urine (2). Isolated hypocitraturia has been identified in about $13 \%$ of patients, and coexists with other metabolic abnormalities in $15 \%$ to $69 \%$ of calcium stone formers $(7,11)$. Hypocitraturia is usually found in patients with systemic acidosis, hypokalemia, unbalanced diets, and chronic diarrhea. The mechanism of action of citrate in the prevention of calcium urolithiasis relates to its ability to form a complex with calcium in urine as calcium citrate complex, which is more soluble than calcium oxalate $(7,12,13)$. The calcium citrate complex prevents all forms of crystallization by inhibiting spontaneous nucleation of calcium oxalate and/or crystal growth of calcium phosphate and calcium oxalate, by retarding agglomeration of preformed calcium oxalate crystal, and by preventing heterogeneous nucleation of calcium oxalate; monosodi- um urate citrate also restores the inhibitory properties of Tamn-Horsfall protein (7).

Several authors supported the benefit of alkaline citrates in all patients undergoing shockwave lithotripsy for the significant improvement in rates of alleviation the calcium oxalate stone-forming activity and positively influence the preexisting stone clearance and dissolution with minor adverse reaction $(2,11,14-16)$. The studies with stone recurrence as the endpoint demonstrated a reduction in stone-forming rate from $47 \%$ to $100 \%$. Of four randomized controlled trials, the stone-free rate after at least two years of alkaline citrate treatment was $53.5 \%$ and $35 \%$ in treatment and placebo groups, respectively (3,14-16). For three years, in idiopathic hypocitraturic calcium nephrolithiasis patients who received potassium citrate, the stone formation per year significantly declined from 1.20.6 to $0.1 \pm 0.2$ stones per patient. This positive effect of potassium citrate also found in calcium stone patients following PCNL (3). Authors concluded that the medical therapy can decrease costs of repeated procedures and recommended it for patients following PCNL regardless of their stone-free status. After potassium citrate, minor gastrointestinal side effects such as diarrhea, indigestion, nausea and burning may occur.

Our study demonstrated that hypocitraturia (urine citrate excretion $<320 \mathrm{mg} / 24$-hours urine) was the most common metabolic risk factor in our patients after ESWL and PCNL. We have found that in these kinds of patients, the medical therapy with potassium-sodium citrate can prevent and/or reduce the recurrence and stone growth during a 12-month follow-up. The patients with residual fragment $<4$ $\mathrm{mm}$ post-treatment were at risk for developing stone growth, as demonstrated in control group compared with the treated group. Our study showed that stonefree status and unchanged stone size status were significantly more frequent in the treated group which is 5.3 fold in stone-free patients and 1.38 fold in CIRF patients as compared to the untreated group. Moreover, the oral formulation of potassium-sodium citrate was well-tolerated with significantly less reported side effects. During the follow-up time, only an increase of serum potassium (but within the normal range), urine $\mathrm{pH}$, and urine citrate were ob- 
served as related with the therapeutic effects of the medication.

The limitations of this study are the small number size and short follow-up time. Due to the poor compliance with alkaline citrate treatment in stone patients with a long follow-up period in clinical practice, this study can demonstrate the positive effect of potassium-sodium citrate in one year follow-up.

\section{CONCLUSIONS}

Hypocitrauria is the most common metabolic disorder in calcium stone patients. Sodium-potassium citrate provides positive effects on stone-forming activities, in a 12- month follow-up in calcium stone patients. We therefore recommend administration of alkali citrates in patients suffering from urolithiasis, following treatment with ESWL and PCNL procedures, for effective prevention of stone recurrence and stone growth.

\section{CONFLICT OF INTEREST}

None declared.

\section{REFERENCES}

1. El-Nahas AR, El-Assmy AM, Madbouly K, Sheir KZ: Predictors of clinical significance of residual fragments after extracorporeal shockwave lithotripsy for renal stones. J Endourol. 2006; 20: 870-4.

2. Soygür T, Akbay A, Küpeli S: Effect of potassium citrate therapy on stone recurrence and residual fragments after shockwave lithotripsy in lower caliceal calcium oxalate urolithiasis: a randomized controlled trial. J Endourol. 2002; 16: 149-52.

3. Kang DE, Maloney MM, Haleblian GE, Springhart WP, Honeycutt EF, Eisenstein EL, et al.: Effect of medical management on recurrent stone formation following percutaneous nephrolithotomy. J Urol. 2007; 177: 1785-8; discussion 1788-9.

4. Mattle D, Hess B: Preventive treatment of nephrolithiasis with alkali citrate--a critical review. Urol Res. 2005; 33: 73-9.

5. Trinchieri A, Ostini F, Nespoli R, Rovera F, Montanari E, Zanetti G: A prospective study of recurrence rate and risk factors for recurrence after a first renal stone. J Urol. 1999; 162: 27-30.

6. Ljunghall S, Danielson BG: A prospective study of renal stone recurrences. Br J Urol. 1984; 56: 122-4.

7. Pattaras JG, Moore RG: Citrate in the management of urolithiasis. J Endourol. 1999; 13: 687-92.

8. Newman DM, Scott JW, Lingeman JE: Two year follow- up of patients treated with extracorporeal shock wave lithotripsy. J Endourol. 1988; 2: 163-71.

9. Ljunghall S: Incidence of upper urinary tract stones. Miner Electrolyte Metab. 1987; 13: 220-7.

10. Fine JK, Pak CY, Preminger GM: Effect of medical management and residual fragments on recurrent stone formation following shock wave lithotripsy. J Urol. 1995; 153: 27-32; discussion 32-3.

11. Stitchantrakul W, Kochakarn W, Ruangraksa C, Domrongkitchaiporn $\mathrm{S}$ : Urinary risk factors for recurrent calcium stone formation in Thai stone formers. J Med Assoc Thai. 2007; 90: 688-98.

12. Pak CY: Citrate and renal calculi: an update. Miner Electrolyte Metab. 1994; 20: 371-7.

13. Pak CY: Medical management of urinary stone disease. Nephron Clin Pract. 2004; 98: c49-53.

14. Barcelo P, Wuhl O, Servitge E, Rousaud A, Pak CY: Randomized double-blind study of potassium citrate in idiopathic hypocitraturic calcium nephrolithiasis. J Urol. 1993; 150: 1761-4.

15. Hofbauer J, Höbarth K, Szabo N, Marberger M: Alkali citrate prophylaxis in idiopathic recurrent calcium oxalate urolithiasis--a prospective randomized study. Br J Urol. 1994; 73: 362-5.

16. Ettinger B, Pak CY, Citron JT, Thomas C, Adams-Huet B, Vangessel A: Potassium-magnesium citrate is an effective prophylaxis against recurrent calcium oxalate nephrolithiasis. J Urol. 1997; 158: 2069-73.

Submitted for publication:

December 01, 2010

Accepted after revision:

May 12, 2011 